\title{
WATER DEMAND ANALYSIS OF MUNICIPAL WATER SUPPLY USING EPANET SOFTWARE
}

\author{
Arunkumar M. ${ }^{1}$, Nethaji Mariappan V.E. ${ }^{2}$ \\ 1 Assistant Engineer, CMWSSB, Chennai, India \\ ${ }^{2}$ Centre for Remote Sensing and Geo informatics,Sathyabama University, Chennai, India \\ Email: 1arun_becivil@yahoo.co.in
}

\begin{abstract}
The study examined the water demand analysis of Public Water Supply in Municipalities using EPANET 2.0 software with the aim of providing effective planning, development and operation of water supply and distribution networks which is one of the most essential components of urban infrastructure. A number of factors ranging from population expansion to inadequate existing facilities are thought to be responsible for the frequent shortage in water supply to the metropolis. The study delineated the areas within the Municipality that are un-served or underserved by the Municipality. Using EPANET 2.0 water model software, the demand for the Underserved and Unserved area is calculated. A framework for taking management decisions such as an extension of the supply network and location of new facilities was given.
\end{abstract}

Key words: Water demand, EPANET 2.0, water allocation model,

\section{INTRODUCTION}

Water makes life possible as without it; life and civilization cannot develop or survive. As man's standard of living increases; so does his need for consumption of water. It is therefore not surprising that early civilizations flourished around river valleys such as those of the Nile in Egypt, Indus in India, Hwangho in China and Euphrates and Tigris in ancient Mesopotamia (Ayoade 1988). In modern times, there is a close relationship between water availability and economic development, especially in the developing countries (Warner, 1995). In India, water availability controls population distribution. Settlements that are provided with modern water supply networks are usually those situated along the major trade and transportation networks and all improved water supply in India is from public water supplies. Though the pattern of water supply varies from one settlement to another, generally as the population of a settlement increases, the service efficiency to the expanding population decreases. This usually creates a great disparity in supply to different zones of the settlement. This problem is more pronounced in the Adjacent Urbanized Areas of Chennai Metropolitan, Tamil Nadu, India.

There is an increasing awareness that water resources exist in limited quantities, and available supply varies considerably during the course of a year. As a result, there is an urgent need to find ways of saving, reusing and recycling water and to develop methodologies to improve water resource management. One long-term strategic goal advocated by several authorities is developing a stable supply of water throughout the year. This goal is consistent with a change in water resources management, which traditionally focused on supply-side policies. In fact, from the 1970s a movement toward demand-control policies has been challenging the expansion of supply capacity to meeting growing needs (Hiessel, 2002). The simultaneous emergence of these goals and paradigms of sustainable water management facilitates the development of constructive applications of new technologies to address these issues.

In terms of personal needs, an average man requires 2.5 litres of water daily for drinking. Apart from drinking, man requires water for various other uses such as cooking, washing, sanitation, agriculture, industrial production, hydro-electric power, etc. To provide for these various uses, the supply of water must meet the demand of the user, be satisfactory in quality and adequate in quantity, be readily available to users, and be relatively cheap and easily disposed of after it has served its purpose. Necessary works are waterworks or water supply systems or waste works or wastewater disposal systems (Chennai, 1978). Waterworks tap natural sources of supply, treat and purify collected water and deliver it to the consumer. Municipal water systems generally comprise: 
- Collection or intake works

- Purification or treatment works

- Transmission and distribution

\section{WATER DEMAND}

\section{A. Existing Water Use}

\section{Definitions}

System water demand is the quantity of water that the treatment plant must produce in order to meet all water needs in the community. Water demand includes water delivered to the system to meet the needs of consumers, water supply for fire fighting and system flushing, and water required to properly operate the treatment facilities. Additionally, virtually all systems have a certain amount of leakage that cannot be economically removed and thus total demand typically includes some leakage. The difference between the amount of water sold and the amount delivered to the system is referred to as unaccounted water. Unaccounted water can result from system flushing, leakage, fire fighting, meter inaccuracies, and other non-metered usage. Water demand varies seasonally with the lowest usage in winter months and the highest usage during summer months. Variations in demand also occur with respect to time of day. Diurnal peaks typically occur during the morning and early evening periods, while the lowest usage occurs during night time hours.

The objective of this section is to determine the current water demand characteristics and to project future demand requirements that will establish system component adequacy and sizing needs. Water demand is described in the following terms:

Average Annual Demand (AAD) - The total volume of water delivered to the system in a full year expressed in litres. When demand fluctuates up and down over several years, an average is used.

Average Daily Demand (ADD) - The total volume of water delivered to the system over a year divided by 365 days. The average use in a single day expressed in Litres per day.

Maximum Month Demand (MMD) - The litres per day average during the month with the highest water demand. The highest monthly usage typically occurs during a summer month.
Peak Weekly Demand (PWD) - The greatest 7-day average demand that occurs in a year expressed in litres per day.

Maximum Day Demand (MDD) - The largest volume of water delivered to the system in a single day expressed in litres per day. The water supply, treatment plant and transmission lines should be designed to handle the maximum day demand.

Peak Hourly Demand (PHD) - The maximum volume of water delivered to the system in a single hour expressed in litres per day. Distribution systems should be designed to adequately handle the peak hourly demand or maximum day demand plus fire flows, whichever is greater. During peak hourly flows, storage reservoirs supply the demand in excess of the maximum day demand.

Demands described above, expressed in litres per day (lpd), can be divided by the population or Equivalent Dwelling Units (EDUs) served to come up with a demand per person or per capita which is expressed in litres per capita per day (lpcd), or demand per EDU (Ipd/EDU). These unit demands can be multiplied by future population or EDU projections to estimate future water demands for planning purposes.

\section{B. Existing Water Demand}

Existing water demand in Avadi Municipality has been determined from daily plant operational records from 2004 through 2007. At the CMWSSB water treatment plant and head works at Avadi, water demand records include quantities of water pumped into the distribution system plus water supplied through mobile supply. On average $95 \%$ of the water received from CMWSSB is sent into the distribution system while $5 \%$ is through mobile supply.

\section{Existing EDU Analysis}

Based on records, the average quantity of water used by a single-family dwelling in Avadi Municipality has been determined. This amount is considered to be the average consumption of 1 equivalent dwelling unit (EDU). When water consumption for other non-residential users is known, a comparison can be made to the consumption for 1 EDU and the number of EDUs for the non-residential user can be determined. 


\section{Unaccounted Water}

The difference between the quantity of water pumped from the water treatment plant into the distribution system and the quantity of water measured at the individual customer water meters (water sold) is unaccounted water. This comparison is typically called a "water balance." Water pumped from the WTP into the system is the amount of water produced minus the amount of water used at the plant for backwashing and other plant use.

Unaccounted water is a combination of "apparent" water loss which results from inaccurate water meters or billing discrepancies and "real" water loss resulting from leakage, water theft, and authorized unbilled usage such as firefighting and main flushing.

If there were no leakage in the system, all water meters were $100 \%$ accurate, and every drop of water used for fire fighting and system flushing was measured, there would be zero unaccounted water. In reality every water system has a certain amount of leakage, water meters are not $100 \%$ accurate, and it is rare for every drop of water used in town to be metered and measured. Therefore virtually every community water system has unaccounted water. To quantify unaccounted water in Newport water sales records are compared to plant production records for a specific time period. Records for the 3-year period from 2004 to 2006 show an average unaccounted water quantity of $15 \%$ of the total water pumped to town from the treatment plant.

\section{PROJECTED WATER DEMAND}

\section{A. Basis for Projections}

Water demand estimates for future years are determined by multiplying the current unit demand design values (Ipcd or Ipd/EDU) by the projected number of future users in the water system. It is assumed new users added to the system will consume water at the same rate as current users. Population and other water user projections are to be presented.

\section{B. Demand Control Policies}

Demand control policies, however, require that water supply agencies establish complete, accurate, and representative information about current water consumption patterns. A realistic assessment of regional water consumption is essential in understanding how water suppliers can accommodate variations in time and type of use. Consumption patterns include a number of water use characteristics representative of the individual users in space and time. These characteristics include, but are not limited to: the number of inhabitants to be supplied with water and their demographics; the consumption habits of the population; the type of development, property size; and property landscape. Each of these (and several other) parameters play a role in explaining overall demand. However data limitations have precluded analysis of the effects that these variables play. Municipalities have relied upon analysis of large-scale consumption patterns to evaluate management options (Forster, 1979; Martin, 1994; Gracia, et. al., 2001). Municipal water managers today are attempting to understand better the general patterns associated to water use in the supply region. Once identified, municipal water suppliers can curtail demand by evaluating alternative demand-oriented management options tailored specifically to those areas. In this paper we propose a methodology that utilizes a Geographic Information System (GIS) and empirical data for analyzing spatial water consumption patterns with the objective of prioritizing water conservation areas within the Avadi Municipality. While the proposed method is applicable to one Avadi Municipality, we foresee application to any Municipality that has the appropriate data. The raw data are publicly available, provided by the Avadi Municipality and CMWSSB.

\section{DISTRIBUTING WATER DEMANDS}

To perform hydraulic modeling, the water demand from each defined sub-region is assigned corresponding demand nodes in the hydraulic model.

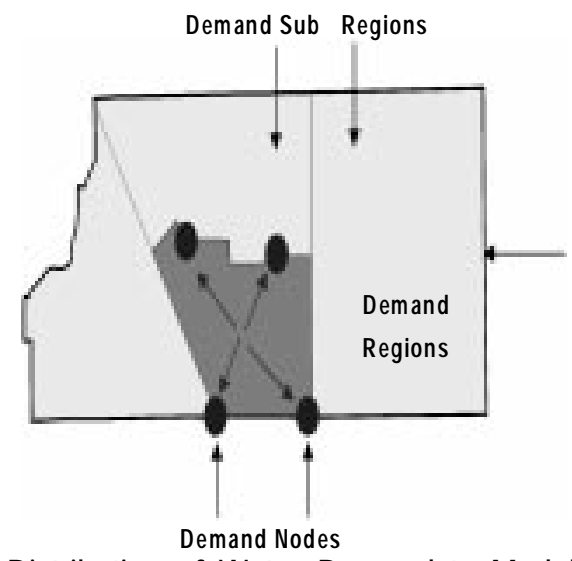

Fig 1. Distribution of Water Demand to Model Nodes 
Generally, water demands are spread uniformly over the demand nodes associated with each sub-region (see Figure 1). Exceptions to the uniform distribution are made in circumstances where it is known that demands are not balanced within demand sub-region.

\section{PEAK WATER USE ESTIMATION:}

Estimation of Average Daily Rate Based on a Maximum Time Period

\section{Goodrich Formula:}

- Estimates maximum demand (expressed as daily water demand based on time period for which maximum water demand is desired) for community when given annual average per capita daily water use rate:

$$
p=180 t^{-0.10}
$$

Where,

$p=$ percentage of average annual rate (volume/day) used in period of time of interest

$\mathrm{t}=$ length of period for which peak demand is required (days) (valid time periods -2 hours to 360 days)

Table 1: Range of Demand Factor

\begin{tabular}{|l|c|}
\hline \multicolumn{1}{|c|}{ Condition } & $\begin{array}{c}\text { Range of } \\
\text { demand factors }\end{array}$ \\
\hline Daily average in maximum month & $1.10-1.50$ \\
\hline Daily average in maximum week & $1.20-1.60$ \\
\hline Maximum daily demand & $1.50-3.00$ \\
\hline Maximum hourly demand & $2.00-4.00$ \\
\hline Minimum hourly demand & $0.20-0.60$ \\
\hline $\begin{array}{l}\text { Source: Velon and joo** (1993). Reprinted by } \\
\text { permission of The McGraw Hill Corporation }\end{array}$ \\
\hline
\end{tabular}

\section{Fire Demand}

In metric units (AWWA 1992):

$$
\mathrm{NFF}=\mathrm{C}_{\mathrm{i}} \mathrm{O}_{\mathrm{i}}(\mathrm{X}+\mathrm{P}) \mathrm{i}
$$

Cis the construction factor based on the size of the building and its construction,
$O$ is the occupancy factor reflecting the kinds of materials stored in the building (ranging from 0.75 to $1.25)$, and

$(X+P)$ is the sum of the exposure factor and the communication factor that reflect the proximity and exposure of the other buildings.

$$
\begin{aligned}
& C_{i}=220 F(A i) \wedge 1 / 2 \\
& C(L / m i n),
\end{aligned}
$$

Hardy Cross Method

- Used in design and analysis of water distribution systems for many years.

- Based on the hydraulic formulas we reviewed earlier in the term.

For Hardy-Cross Analysis:

- Water is actually removed from the distribution system of a city at a very large number of points.

- Its is not reasonable to attempt to analyze a system with this degree of detail

- Rather, individual flows are concentrated at a smaller number of points, commonly at the intersection of streets.

- The distribution system can then be considered to consist of a network of nodes (corresponding to points of concentrated flow withdrawal) and links (pipes connecting the nodes).

- The estimated water consumption of the areas contained within the links is distributed to the appropriate nodes

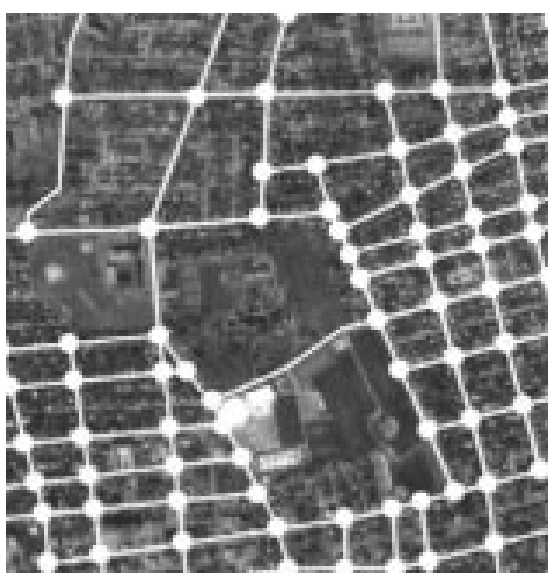

Fig. 2 Network model overlaid on aerial photograph 


\section{EPANET}

EPANET is a computer program that performs extended period simulation of hydraulic and water quality behavior within pressurized pipe networks. A network consists of pipes, nodes (pipe junctions), pumps, valves and storage tanks or reservoirs. EPANET tracks the flow of water in each pipe, the pressure at each node, the height of water in each tank, and the concentration of a chemical species throughout the network during a simulation period comprised of multiple time steps. In addition to chemical species, water age and source tracing can also be simulated. EPANET is designed to be a research tool for improving our understanding of the movement and fate of drinking water constituents within distribution systems. It can be used for many different kinds of applications in distribution systems analysis. Sampling program design, hydraulic model calibration, chlorine residual analysis, and consumer exposure assessment are some examples. EPANET can help assess alternative management strategies for improving water quality throughout a system. These can include:

1. altering source utilization within multiple source systems,

2. altering pumping and tank filling/emptying schedules,

3. use of satellite treatment, such as re-chlorination at storage tanks,

4. targeted pipe cleaning and replacement.

Running under Windows, EPANET provides an integrated environment for editing network input data, running hydraulic and water quality simulations, and viewing the results in a variety of formats. These include color-coded network maps, data tables, time series graphs, and contour plots.

\section{Hydraulic Modeling Capabilities}

Full-featured and accurate hydraulic modeling is a prerequisite for doing effective water quality modeling. EPANET contains a state-of-the-art hydraulic analysis engine that includes the following capabilities:

1. places no limit on the size of the network that can be analyzed

2. computes friction headloss using the Hazen-Williams, Darcy- Weisbach, or Chezy-Manning formulas
3. Includes minor head losses for bends, fittings, etc.

4. models constant or variable speed pumps

5. computes pumping energy and cost

6. models various types of valves including shutoff, check, pressure regulating, and flow control valves

7. allows storage tanks to have any shape (i.e., diameter can vary with height)

8. considers multiple demand categories at nodes, each with its own pattern of time variation

9. models pressure-dependent flow issuing from emitters (sprinkler heads)

10. can base system operation on both simple tank level or timer controls and on complex rule-based controls.

\section{Water Quality Modeling Capabilities}

In addition to hydraulic modeling, EPANET provides the following water quality modeling capabilities:

1. models the movement of a non-reactive tracer material through the network over time

2. models the movement and fate of a reactive material as it grows (e.g., a disinfection by-product) or decays (e.g., chlorine residual) with time

3. models the age of water throughout a network

4. tracks the percent of flow from a given node reaching all other nodes over time

5. models reactions both in the bulk flow and at the pipe wall

6. uses n-th order kinetics to model reactions in the bulk flow

7. uses zero or first order kinetics to model reactions at the pipe wall

8. accounts for mass transfer limitations when modeling pipe wall reactions

9. allows growth or decay reactions to proceed up to a limiting concentration

10. employs global reaction rate coefficients that can be modified on a pipe-by-pipe basis 
11. allows wall reaction rate coefficients to be correlated to pipe roughness

12. allows for time-varying concentration or mass inputs at any location in the network

13. models storage tanks as being either complete mix, plug flow, or two-compartment reactors.

By employing these features, EPANET can study such water quality phenomena as:

1. blending water from different sources

2. age of water throughout a system

3. loss of chlorine residuals

4. growth of disinfection by-products

5. Tracking contaminant propagation events.

\section{Steps in Using EPANET}

One typically carries out the following steps when using EPANET to model water distribution system:

1. Draw a network representation of your distribution system or import a basic description of the network placed in a text

2. Edit the properties of the objects that make up the system

3. Describe how the system is operated

4. Select a set of analysis options

5. Run a hydraulic/water quality analysis

6. View the results of the analysis.

The current water demand characteristics and the future demand requirements that will establish system component adequacy and sizing needs are analyzed using EPANET 2.0 software.

\section{POPULATION PROJECTION AN EXAMPLE}

The details of the population as obtained from Statistical Department for the Population of this Municipality for the years 1981 to 2001 are furnished in the following table.
Table 4

\begin{tabular}{|c|c|c|}
\hline S.No & Statistical Year & Population in Lakhs \\
\hline 1 & 1981 & 1.24 \\
\hline 2 & 1991 & 1.83 \\
\hline 3 & 2001 & 2.16 \\
\hline
\end{tabular}

Population projection for the design period of 30 years has been worked out by the following methods as stipulated in the CPHEEO Manual for Water Supply.

(a) Arithmetical Method

(b) Geometrical Progression method

(c) Graphical projection method

The base year is taken as 2008 and the design intermediate and ultimate years are taken as 2023 and 2038 respectively. The projection of the population made with reference to the details of population obtained from Statistical Department for the years 2008, 2023 and 2038 works out to 2.70 lakhs, 3.34 lakhs and 4.29 lakhs respectively. The municipality furnished ward-wise population. Its population projection has been made in proportion to overall projection computed for the municipality.

\section{Water Demand}

Taking per capita supply as 155 lpcd as per CPHEEO norms (135 lpcd $+15 \%$ for unaccounted for flow), the water demand for the years 2008, 2023 and 2038 works out to $41.85 \mathrm{MLD}, 51.78 \mathrm{MLD}$ and 66.50 MLD respectively. The zoning should be done geometrically with reference to the locations of the Head works accordingly. The population and demand for each zone should be computed.

\section{Distribution system}

Coverage of area by zoning for operation of Headworks

As per the locations of the head works, the entire area should be divided into zones. Accordingly laying of distribution mains in the streets/roads of should be proposed.

As the population of the municipality is not evenly distributed, The population projection for each zone should be made with reference to the present 
population. Accordingly, the demand should be projected and distribution system has to be designed.

Designing distribution network using EPANET version 2.0

Hydraulic design for the distribution system using Loop version 4.0 has been carried out and the same is analyzed using EPANET2.0 and is shown in fig.

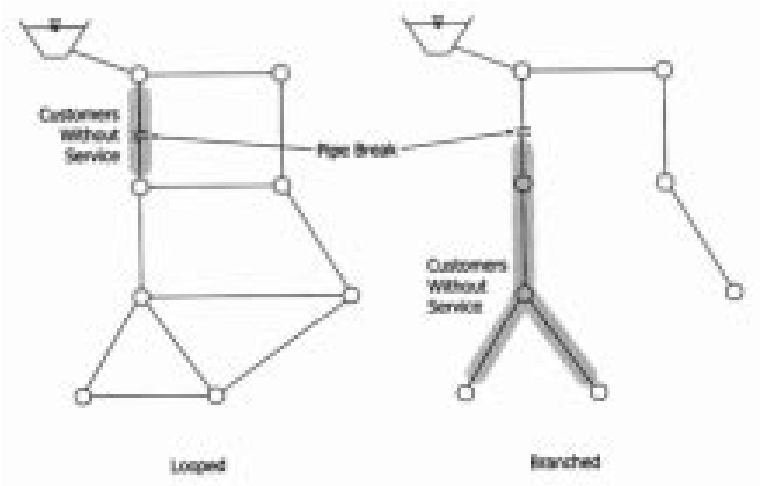

Fig. 3. Looped and branched networks after network failure

Design approach adopted for distribution system

For efficient and equitable distribution of water, a grid pattern where different mains are interconnected keeping dead ends to a minimum is recommended. This system facilitates for supply of water to any one point in the grid at least from two different directions. Where the growth of the town has not been orderly planned, with several pockets just in developing stage and some areas still remaining agricultural/vacant lands, the distribution system is designed for future demand in such a way to supply water from the adjacent grid to the later developments. Theoretical future demand based on the density of the present population is proposed for the feeders where streets are not formed. Hence the distribution pipes can be extended as and when development takes place. The system is designed for the projected population for the year 2038 and for the per capita supply at $155 \mathrm{lpcd}$. As per the CPHEEO Manual for Treatment and Water supply, a peaking factor of 3.0 has been applied. The details of population and demand of water for the ten zones are worked out and furnished in ANNEXURE-II

\section{Hydraulic criteria}

Hydraulic criteria used for the Net work analysis are as below:

Design period: 30 years
Percapita : 155 lpcd (as per norms of CPHEEO)

Minimum

Residual Head: $12 \mathrm{~m}$

Hazen Williams

Coefficient : 140 for DI pipes

Peak factor : 3

Analysis

Software : Epanet 2.0

Pipe Material \& size

There are two materials of pipes are considered for providing distribution system. i.e DI and PVC pipes. DI pipes have excellent properties of machinability, impact resistance, high wear and tear resistance, high tensile strength \& ductility and corrosion resistance. The DI pipes are strong, both inner and outer surfaces are smooth and are about 30\% lighter than conventional $\mathrm{Cl}$ pipes. Thus, $\mathrm{Dl}$ pipes are ideal for providing distribution system considering the durability and other factors. But the pipe cost is more compared to PVC pipes and thus leads to higher Project cost. The initial project investment using PVC pipes is cheaper. But PVC pipes are sensitive to point loading and also to impact and dynamic loading conditions. In urban and semi urban areas, there is a possibility of frequent 'dig-in' and transferring by other departments. Hence considering the above pros and cons, it is considered ideal to have DI pipes of K7 class.

Composition of pipes of various dia in distribution system: -

As per the loop/Epanet 2.0 design, run out for distribution system should be carried out for the entire area and the pipes required for the zones should be arrived.

\section{Appurtenances}

\section{Sluice valves}

Sluice valves are provided in such a way to isolate a portion of distribution network to regulate the flow which enabled easy maintenance in future. The locations of sluice valves are shown in the drawing.

\section{Air valve}

Air valves should be provided at suitable locations wherever it is warranted. 


\section{RESULTS ON MODEL IMPLEMENTATION}

This chapter is a discussion of the implementation of Hydraulic workflow model on the case study area data and the results of the analysis. This model is implemented on the data using EPANET software Version 2.0. We have data of Avadi Municipality and we will be implementing the proposed model on the case study area.

The first analysis is designing the distribution network for the Thirumullaivoyal A zone of Avadi Municipality for $24 \mathrm{Hrs}$ supply with a design period of 30 years Using the EPANET Version 2.0 and the size of pipes required for $24 \mathrm{Hrs}$ supply are found as stated above. After application of the software the following results were obtained.

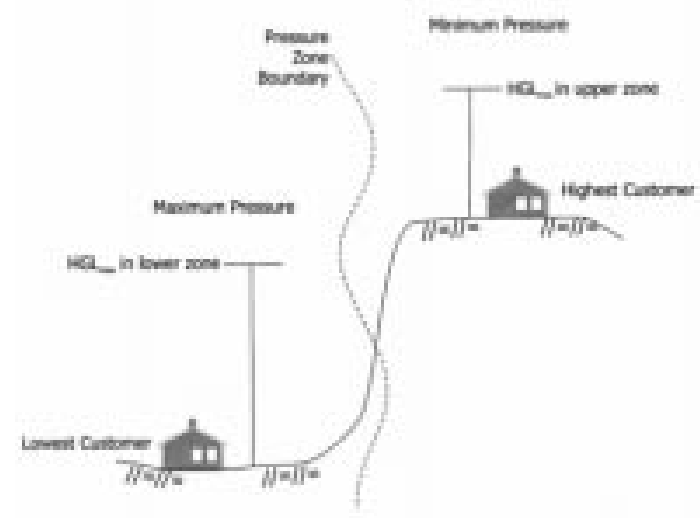

Fig.4 Customers must be served from separate pressure zones

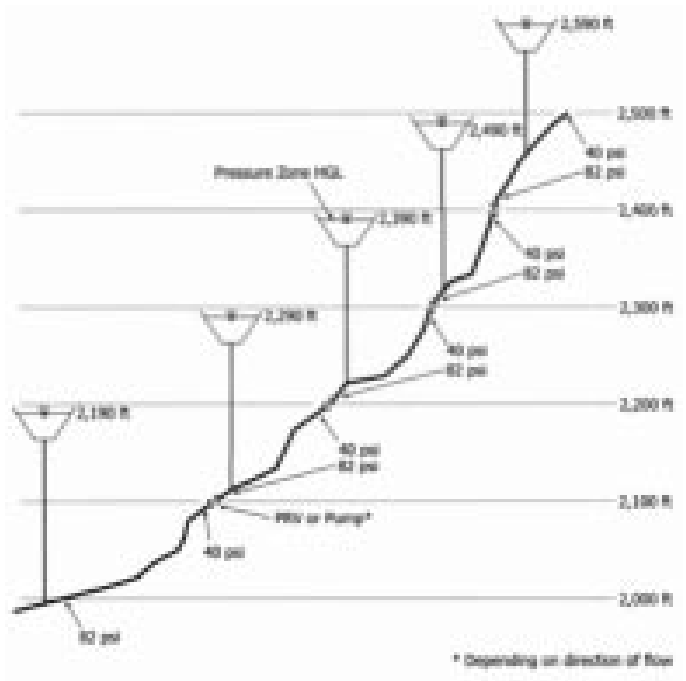

Fig. 5 Profile of pressure zones

\section{Summary for 24 Hrs supply}

1. Number of Junctions

2. Number of Tanks

3. Number of Pipes

4. Flow Units

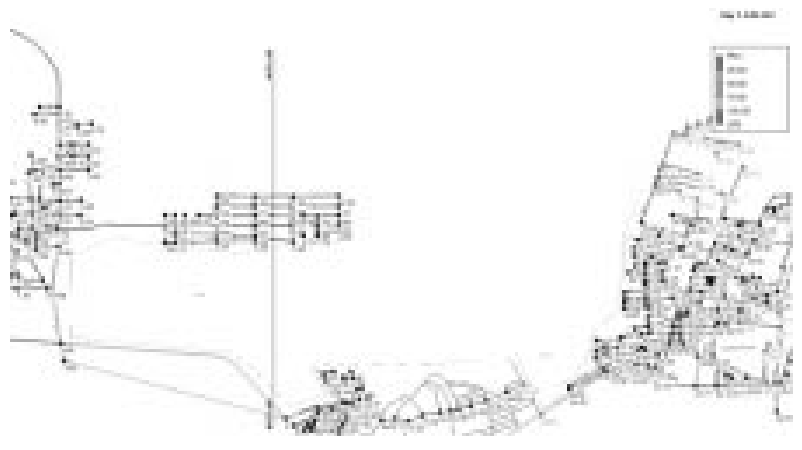

Fig 6 Network Analyzed for 24 Hrs Supply

During the analysis it is found that system shows negative pressure while running the same network for intermittent supply.

As far as the Chennai Metropolitan Water Supply and Sewerage Board and Avadi Municipality is concerned they are not providing $24 \mathrm{Hrs}$ supply to the consumers (Public, Institutions, industry etc.,). Hence as an improvement over the first analysis the same network is analysed using EPANET version 2.0 for intermittent supply say $6 \mathrm{Hrs}$ by introducing a PB vale in the first link. As a result of this the network runs successfully with difference in pressure time to time.

Eg. 1. Pressure at node 211 for $24 \mathrm{hrs}$ supply $=12.02 \mathrm{~m}$

2. Pressure at node 211 for 06 hrs supply $=24.03 \mathrm{~m}$

\section{Summary for 6.00 hrs supply}

$\begin{array}{lr}\text { Number of Junctions } & 527 \\ \text { Number of Tanks } & 1 \\ \text { Number of Pipes } & 624 \\ \text { Number of Valves } & 2 \\ \text { Flow Units } & \text { LPS }\end{array}$




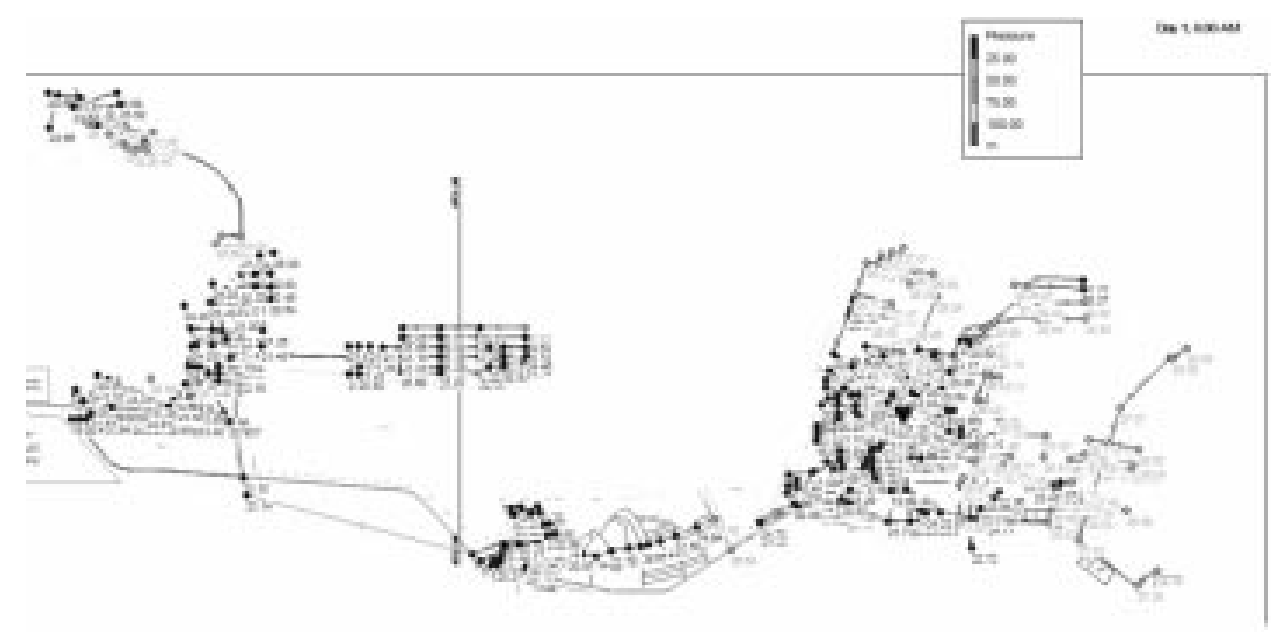

Fig 7 Network Analyzed for 6 Hrs Supply

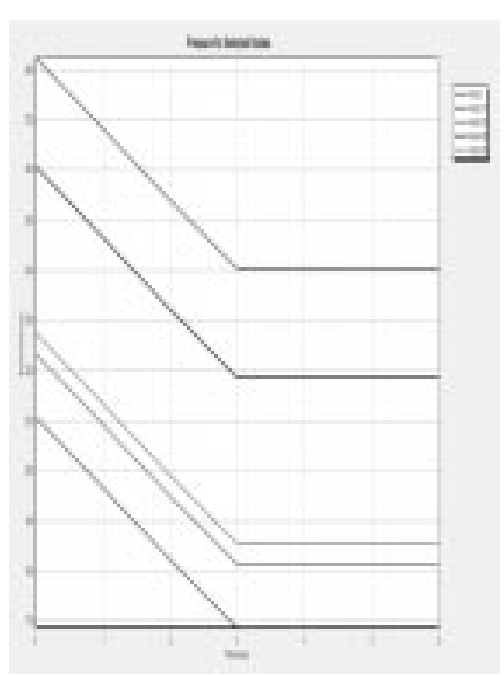

Fig 8 Pressure at selected Nodes

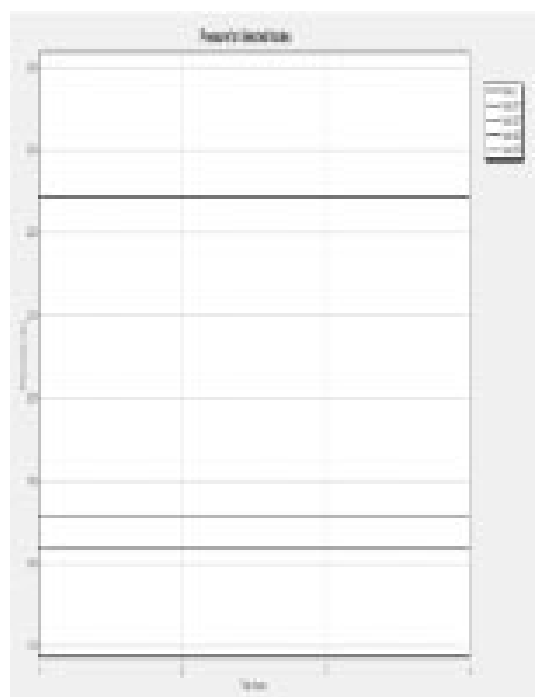

Fig. 10 A Pressure at selected Nodes

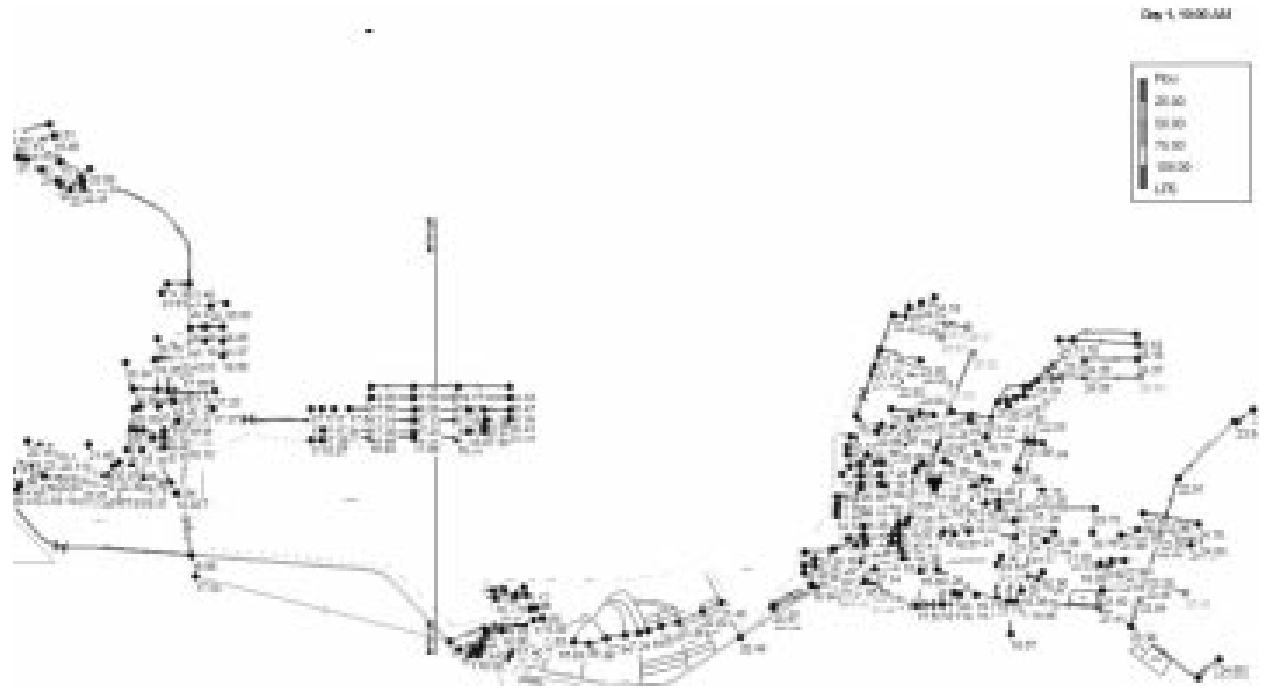

Fig.9 Network Analyzed for Intermittent Supply - at $4.00 \mathrm{Hrs}$ 
Since there is a variation in pressure at some nodes of the network, once again the network is analysed using EPANET 2.0 for $6 \mathrm{Hrs}$ supply by introducing 39 nos of Pressure regulating valves at different links in the network. As a result even pressure is maintained at all the nodes for the entire supply time of 6.00 Hour.

Eg. 1. Pressure at node 211 for 24 hrs supply $=12.02$ m (First Analysis)

2. Pressure at node 211 for 06 hrs supply $=24.03 \mathrm{~m}$ (Second Analysis - changes from time to time)

3. Pressure at node 211 for 06 hrs supply $=24.18 \mathrm{~m}$ (Third Analysis - constant for the entire supply period)

\section{Summary for 6.00 hrs supply}

1. Number of Junctions

527

2. Number of Tanks

1

3. Number of Pipes

624

4. Number of Valves

39

5. Flow Units

LPS

\subsection{DISCUSSION}

The Hydraulic model EPANET version 2.0 is used for designing the optimized water supply system to the case study area. There were several aspects taken into consideration in planning the water supply system. First was to analyse the network for 24 hours supply and the consumer satisfaction in obtaining the water at the tail end without any loss of pressue. The network was analysed for intermittent supply because CMWSSB and Avadi Municipality are not providing 24 hours water supply to the public. The network shows negative pressure when analysed for intermittent supply. At present the network may function efficiently for the intermittent supply but not for the entire design period of 30 years (i.e upto 2038). The planning concern was to verify the whether the end users get the water at required minimum pressure of $12 \mathrm{~m}$ as stated by CPHEEO.

Secondly the distribution network was balanced for intermittent supply (i.e for 6 hours) by introducing
PBV at link 1 and some sluice valves in the network.the result of analysis shows that the pressure at the node are $>12 \mathrm{~m}$, but it get decreased for the due course of time as shown in Figure 8. This was done by checking the Network using the EPANET 2.0 software.

Once again the distribution network was balanced for intermittent supply (i.e for 6 hours) by introducing PRV and SV in the network for maintaining even pressure at all nodes through out the supply time. As a result of introducing PRV the pressure was maintained above the threshold value of $12 \mathrm{~m}$ as mentioned by the CPHEEO at the tail ends as shown in the figure 9 and 10 . Managing the study with the available set of information and also not ignoring the important aspect of public/consumer satisfaction. It is a generalised proposal with a margin of flexibility for changes and up gradation as per the situational changes or preferences.

\subsection{Recommendations and Future Studies}

There are several issues that can be considered for future studies. The important issue it to first takes those ones which can be practically possible to implement in the area with the consideration of the system constrains. Here are some future study suggestions which can be adopted as a next step to the proposed model for the study area.

- Study the statistics of quantity of water used in different areas for planning water conservation and Drought management in a more precise manner.

- Analysis of further requirement of strengthening of the netwok i.e distribution system for any specific land use or any area.

- The study of revenue generation by metering all the consumer and taken into account the UFW.

- Water quality analysis and monitoring using GIS concepts.

The main aim is to provide adequate water to the consumers (Public, Institutions, Industry etc.,) in an economic way. There can be lot of advancements in the system but it have to be carried in stages according to the availability of resources. 


\section{ACKNOWLEDGEMENT}

I am heartily thankful to my supervisor, Dr. V. E. Nethaji Mariappan, Scientist, Centre for Remote Sensing, whose encouragement, guidance and support from the initial to the final level enabled me to develop an understanding of the subject and for his detailed and constructive comments, and for his important support throughout this work.

Lastly, I offer my regards and blessings to all of those who supported me in any respect during the completion of the project.

\section{REFERENCES}

1. CPHEEO (1999) "Manual on Water Supply and Treatment" published by Central Public Health and Environmental Engineering, New Delhi, India

2. AWWA. Water Resources Planning - AWWA Manual M50.American Water Works Association, Denver,Co.2001Training Manual

3. Vanasse Hangen Brustlin, Inc. Raw Water Supply Facility Permitting - Demand Analysis.October 1997.

4. Water Demand and Supply Analysis using a Spatial Decision Support System, E.Manoli, Global Nest: the int. J. Vol 3, No. 3, pp199-209, 2001

5. Detailed project report of Avadi Municiaplity Water Supply Scheme, Volume 1 from CMWSSB

6. Simonovic, S.P (2000), Tools for Water Management One View of the Future, IWRA Water International, 25, 76-88.

7. Bhave, P. R.(1991) Analysis of Flow in Water Distribution Network Technique Publishing inc, Lancaster

8. Water Utilities Data Book for the Asian and Pasific Region, 1997
9. McGhee, Terence J. 1991. Water supply and Sewarage, $6^{\text {th }}$ Edition. McGraw Hill Inc. New York

10. McIntosh, Arthur C., Yniguez, Cesar E. 1997. Second Water Utilities Data Book - Asian and Pacific Region, Asian Development Bank

11. WHO. 1993. Guidelines for drinking water quality. Volume 1, Recommendations.

12. Arbues, F., Garacia - Valinas, M. and Martinez-Espineria, R. (2003). Estimation of residential water demand:A state of the art review, Journal of Socio-Economics 32, 81-102.

13. Renwick, M., and Archibald, S. (1998). Demand side management policies for residential water use: Who bears the conservation burden? Land Economics 74, 343-359

14. Creedy, J., van de Ken, J. and MvKenzie, K. (1998). The demand for water by single-metered and group metered households, the Australian Economic Review 31, 203-210

15. Dandy, G., Nguyen, T. and Davies, C. (1997). Estimating residential water demand in the presence of free allowances, Land Economics 73, 125-139.

16. Dinar, A. and Subramaniam, A. (eds.) (1997). Water pricing experiences, World Bank Technical Paper, No. 386, Available From URL://www.worldbank.org/ [accessed March 2005].

17. EPANET Manual

18. Water Evaluation and Planning System, User Guide, Stockholm Environmental Institute, Tellus Institute, Bostan, USA

19. Foster, H.S.J., Beattie, B.R., 1979. Urban residential water demand for the water in united states. Land Economics 55(1)pp. 43-58

20. http://www.sebi.org/weap

21. URL://www.worldbank.org/[accessed March 2005]

22. http://www.usepa.gov 